\title{
Eco-evolution in size-structured ecosystems: simulation case study of rapid morphological changes in alewife
}

Jung koo Kang ${ }^{1,2}$ and Xavier Thibert-Plante $2^{2^{*}}$ (i)

\begin{abstract}
Background: Over the last 300 years, interactions between alewives and zooplankton communities in several lakes in the U.S. have caused the alewives' morphology to transition rapidly from anadromous to landlocked. Lakes with landlocked alewives contain smaller-bodied zooplankton than those without alewives. Landlocked adult alewives display smaller body sizes, narrower gapes, smaller inter-gill-raker spacings, reach maturity at an earlier age, and are less fecund than anadromous alewives. Additionally, landlocked alewives consume pelagic prey exclusively throughout their lives whereas anadromous alewives make an ontogenetic transition from pelagic to littoral prey. These rapid, well-documented changes in the alewives' morphology provide important insights into the morphological evolution of fish.

Predicting the morphological evolution of fish is crucial for fisheries and ecosystem management, but the involvement of multiple trophic interactions make predictions difficult. To obtain an improved understanding of rapid morphological change in fish, we developed an individual-based model that simulated rapid changes in the body size and gill-raker count of a fish species in a hypothetical, size-structured prey community. Model parameter values were based mainly on data from empirical studies on alewives. We adopted a functional trait approach; consequently, the model explicitly describes the relationships between prey body size, alewife body size, and alewife gill-raker count. We sought to answer two questions: (1) How does the impact of alewife populations on prey feed back to impact alewife size and gill raker number under several alternative scenarios? (2) Will the trajectory of the landlocked alewives' morphological evolution change after 150-300 years in freshwater?

Results: Over the first 250 years, the alewives' numbers of gill-rakers only increased when reductions in their body size substantially improved their ability to forage for small prey. Additionally, alewives' gill-raker counts increased more rapidly as the adverse effects of narrow gill-raker spacings on foraging for large prey were made less severe. For the first 150-250 years, alewives' growth decreased monotonically, and their gill-raker number increased monotonically. After the first 150-250 years, however, the alewives exhibited multiple evolutionary morphological trajectories in different trophic settings. In several of these settings, their evolutionary trajectories even reversed after the first 150-250 years.
\end{abstract}

Conclusions: Alewives affected the abundance and morphology of their prey, which in turn changed the abundance and morphology of the alewives. Complex low-trophic-level interactions can alter the abundance and characteristics of alewives. This study suggests that the current morphology of recently ( $~ 300$ years)-landlocked alewives may not represent an evolutionarily stable state.

Keywords: Eco-evolution, Size-structured ecosystem, Individual-based model, Ecological power law, Contemporary evolution, Functional trait, Body size, Fish, Alewife

\footnotetext{
*Correspondence: xavier@thibert-plante.com

${ }^{2}$ Icelab and Department of Ecology and Environmental Science, Umeå University, Linnaeus văg 6, Umeå, Sweden

Full list of author information is available at the end of the article
} 


\section{Background}

\section{Functional trait approaches for studying rapid morphological evolution in fish}

Predator-prey interactions affect contemporary evolutionary processes such as the rapid morphological changes observed in several fish species [1-4]. Predicting morphological changes in fish is crucial for fisheries and ecosystem management, but such changes are affected by a complex set of trophic interactions, which makes accurate prediction very difficult.

Functional trait approaches have been widely used to study the effect of the disturbance caused by a species on a community [5-7], but they can also be used to study how the evolution of one species in a community is affected by the other species that are present. Functional traits strongly affect organismal performance [8], so changes in species' functional traits can affect the abundance of its predators and prey, which in turn alters its fitness landscape. For example, predator morphology can determine the size of prey that predators consume [9]. Conversely, prey size distribution can influence predator size distribution [10]. By extension, entire communities can be analyzed by studying the functional abilities of both the assemblage as a whole and the component species individually [5-7].

\section{Rapid changes in alewife morphology}

The morphological transition of alewives, Alosa pseudoharengus (Wilson), in isolated freshwater ecosystems provides a well-documented empirical illustration of the relationship between functional trait evolution in fish and changes in the zooplankton communities of the fishes' environment [3]. Over a period of 45-300 years, alewife populations trapped in freshwater ecosystems have undergone a transition from an anadromous to a landlocked morphology, which has been attributed to their interactions with zooplankton communities [11]. Alewives are the dominant force structuring zooplankton communities in eastern North American lakes [12-14]; for example, lakes with landlocked alewives contain smaller-bodied zooplankton than those without alewives [12, 13, 15-18]. Anadromous alewives migrate from salt water to spawn in fresh water and reside in fresh water for approximately six months per year. In contrast, landlocked alewives do not leave freshwater [19]. In lakes with migratory anadromous alewives, the zooplankton community shifts annually between being dominated by large-bodied organisms in the spring and small-bodied organisms in the summer [20]; in lakes with resident landlocked alewives, the zooplankton remain small throughout the year because of stable predation pressure [20].

Alewives have been landlocked in multiple lakes for the past $\sim 300$ years for multiple reasons including dam construction $[3,12,21]$. They were observed in Lake Ontario as early as 1880 [22], and were first recorded in Lake Michigan in 1949 [23]. Today, landlocked alewives are found in the Great Lakes and several of the Finger Lakes of New York [22]. The rapid expansion of alewife populations in the upper Great Lakes disturbed the native fish fauna, causing early summer die-offs of alewives around Milwaukee, Wisconsin, and other cities on the Great Lakes [22]. In Lakes Michigan, Huron, and Ontario, managers are confronted with the challenge of maintaining adequate numbers of alewives to support salmonine stocks while reducing alewife abundance sufficiently to permit the restoration of native fish species [24].

Landlocked alewives show a consistent pattern of lifehistory divergence from anadromous alewives: landlocked adult alewives have smaller bodies, narrower gapes, smaller inter-gill-raker spacings, lower fecundity, and reach maturity at an earlier age than anadromous alewives $[3,18,25]$. Landlocked alewives also consume exclusively pelagic prey and retain their pelagic niche throughout their lives [26] whereas anadromous alewives consume approximately equal proportions of littoral and pelagic prey, and make an ontogenetic transition from the one to the other [26]. These differences in prey preferences across developmental stages are one potential cause of the morphological differentiation between anadromous and landlocked alewives $[26,27]$. The differences in the environmental requirements of landlocked and anadromous populations are currently unknown [28].

Anadromous alewives range from North Carolina to Newfoundland [29]. They spawn along the Atlantic coast from late March through July, and spawning occurs at progressively later dates in more northerly regions [28, 30]. During spawning, 3-to-4-year-old males are abundant, while females dominate among older fish [28]. Males mature earlier than females but have shorter lifespans [28]. Alewives are iteroparous, and females lay nearly all of their eggs during spawning [28]. The alewife absorption stage lasts for 2-5 days [31]. Juveniles typically rear in freshwater for several months before migrating to the ocean between June and November, and they mature at 3-6 years of age $[32,33]$. Alewives exhibit olfactory-sensory-driven homing behavior [34] but are not known to show any fidelity to their natal river [35], and there is significant mixing among alewife populations [36].

Alewives play important roles in freshwater and saltwater ecosystems. They feed primarily on zooplankton; the larvae begin to feed on small cladocerans and copepods immediately after developing a functional mouth [28]. They also forage for fish eggs and larvae, and cause native planktivores to go into decline [37-41]. Large alewives feed on small fish, insects, and crustaceans $[14,42]$. In turn, they are prey for several piscivores, including bluefish, Pomatomus saltatrix, weakfish, Cynoscion regalis, striped bass, Morone saxatilus, dusky 
shark, Carchahinus obscurus, spiny dogfish, Squalus acanthias, salmon, Salmo salar, monkfish, Lophius gastrophysus, cod, Gadus morhua, pollock, Pollachius virens, and silver hake, Merluccius bilinearis [43]. For stream food webs, anadromous alewives are a potentially important source of marine-derived nitrogen [44]. Because of their ecological importance and low abundance, alewives were declared a Species of Concern by the National Marine Fisheries Service (NMFS) between 2005 and 2007. Harvest restrictions on alewives were imposed in all coastal states, including Massachusetts, Rhode Island, Connecticut, and North Carolina, from 2012 [33].

\section{Modeling rapid morphological changes of alewives}

To improve our understanding of rapid morphological changes in fish, we developed an individual-based model that simulates rapid changes in the body size and gill raker count of a fish species in a hypothetical, size-structured prey community. We adopted a functional trait approach when developing the model; it explicitly describes the relationships between prey size, fish body size, and fish gill-raker count. Ecological power laws [45] were used to define the relationships between the prey-predator body mass ratio and trophic interactions [46-49], between body mass and abundance [50], and between body mass and metabolic rate [51].

Here we report the use of this model to address two questions: (1) How does the impact of alewife populations on prey feed back to impact alewife size and gill raker number under several alternative scenarios? (2) Will the trajectory of landlocked alewives' morphological evolution change after $150-300$ years in freshwater?

\section{Methods}

\section{Model overview}

We combined an individual-based model and difference equations to describe alewives, their prey, and their interactions. The time step of the simulations was one year, and each simulation was allowed to run for 5000 simulated years. Ten replicates of each individual simulation were performed. Model parameter values were derived mainly from empirical studies of alewives.

At each time step, each individual alewife either survives without developing, survives and develops, or dies. Their body size increases stochastically (Algorithm (SI.1)). As an individual grows, their resource requirements for survival, foraging efficiency for different prey sizes, and sexual maturation status changes. The survival of an individual depends on their metabolic rate and foraging ability, the level of resource competition, and prey abundance. A Beverton-Holt function is used to describe the effect of prey mass and fish metabolic rate on densitydependent fish survival (Eq.(SI.16)). There are trade-offs between fish body size and gill-raker spacing that affect the fishes' foraging, survival, and reproduction. Alewives breed once a year and show iteroparity. The proportion of newborn female offspring is set to 0.5 because the sex ratio of alewives is approximately $1: 1$ [28]. Anadromous and landlocked alewife populations have a polygynandrous (promiscuous) mating system; therefore, the two ecotypes do not typically co-exist in the same lake [3]. Thus, in the model, each sexually mature female randomly selects a sexually mature male for mating (Algorithm (SI.2)).

The fish forage for different-sized prey; the available prey is conceptualized as a set of size-structured clusters that are described using difference equations. The abundance of prey clusters is influenced by the competition within a prey cluster (i.e. a trophic level), the extent of foraging for smaller-bodied prey clusters, the predation by larger-bodied prey clusters, and foraging by the alewives (Fig. 1).

The following subsections outline the model's core processes. Additional details of the model are presented in Additional file 1: Supporting information (SI) I, while Additional file 1: Supporting information II provides a list of symbols used in this work and the default input parameter values. We used local sensitivity analyses to determine how uncertainty in the model's input parameter values affected its outputs. The parameter values used in these local sensitivity analyses are presented in Additional file 1: Supporting information II. The default input parameter values were used at all times in the local sensitivity analyses except where stated otherwise.

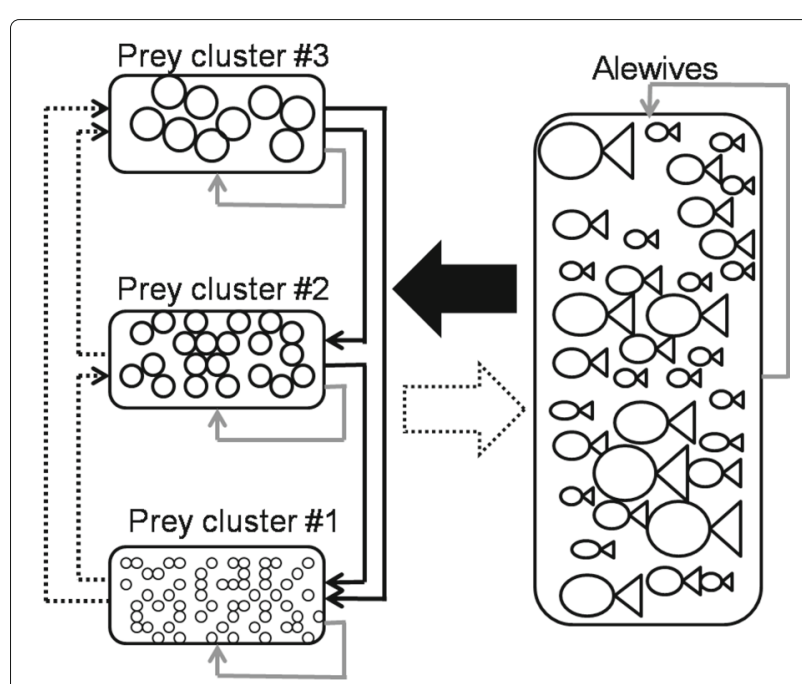

Fig. 1 Ecological interactions in the model. A solid black arrow from A to $B$ indicates foraging for prey $B$ by predator $A$. A dashed black arrow from $A$ to $B$ indicates an increase in the population growth of predator B foraging for prey A. A solid grey arrow indicates competition 


\section{Alewife genetics}

Alewives are sexually reproducing diploid organisms. Gill raker number is a heritable trait in most fishes [52, 53]. In our model, the first and second sets of unlinked biallelic quantitative trait loci (QTLs) $(\{0,1\})$ influence the body size and the gill-raker count, respectively. A trait is determined by the relative abundance of allele 1 to the total number of alleles in the loci controlling the trait. The default number of loci for a trait is eight, and the mutation rate for alleles is $10^{-5}$.

\section{Alewife body size}

A stochastic, density-dependent extension of the von Bertalanffy growth function [54] is used to compute the increase in each individual's body size over each time step. In general, the model assumes that growth is dependent on the growth-affecting QTLs and the environment (Eq.(SI.10)). However, to facilitate analysis of the model's default behavior, we only simulated the genetic effect on growth. With environmental effects excluded, the parameter $b A$ (default value $=0.25$ ) controls the magnitude of each growth-facilitating allele's effect. We studied the effect of $b A$ on alewife morphological evolution by performing a local sensitivity analysis. The default parameter values for the growth process set the average body length of the largest 5-year-old females to approximately the average total body length of adults from three anadromous populations $(=260 \mathrm{~mm})$ and the average body length of the smallest 2-year-old females to a value somewhat lower than the average total body length of adults from three landlocked populations $(=97 \mathrm{~mm})[3]$. The coefficient of variation for growth, $b c v$ (default value = 0.01)(Eq.(SI.8)), controls the individual stochasticity of growth. We tested multiple values $(0.001,0.01,0.1,0.2)$ of $b c v$ in a local sensitivity analysis to study the effect of the individual stochasticity of growth on fish morphological evolution.

Some landlocked alewives may spawn at the age of 2 years [55], but 3-to-10-year-old adults dominate anadromous alewife spawning grounds [28, 32, 56, 57]. We therefore assumed that growth-facilitating alleles delayed sexual maturation. Additionally, fertility in many fish species increases with body size $[58,59]$. Therefore, in our model, the mean number of offspring produced by a female increases with the female's body mass (Eq.(SI.30)).

Body size and prey size are positively correlated in many fish species [60-65], including alewives [66]. Accordingly, in our model, an individual's body size affects the efficiency of their foraging for large prey, $u$. This relationship is described by Eq. (1).

$$
u_{i}(t)=0.01\left[10^{-5.289}\left(b O_{i}(t)^{3.063}\right)\right]
$$

where $b O$ is body length $(\mathrm{mm})$, which is used to calculate the available prey mass for an individual (Eq.(SI.15));
$10^{-5.289}$ and 3.063 are the constant and exponent used to convert body length $(\mathrm{mm})$ to body mass $(\mathrm{g})$, respectively [67]; 0.01 is the default value of the multiplier used to calculate the efficiency of alewives' foraging for large prey based on body mass. This parameter also regulates the ability of anadromous alewives that are at least one year old to forage for fish eggs $(0.1-0.2 g)$. Gape size was assumed to be allometrically related to body mass.

\section{Gill raker}

The role of a gill raker apparatus is related to prey retention efficiency [68-70]. Small inter-gill-raker spacings limit the ability of small prey to escape [4], and crossflow filtering capacity increases with the gill-raker count [4]. For a given number of gill rakers, the inter-gill-raker spacing increases with body size $[3,71,72]$. Moreover, for alewives, the probability of capturing small prey increases as the total body length decreases [71]. Equation (2) describes how the gill-raker spacing, $l$ (which controls the efficiency of foraging for small prey), decreases as the gill-raker count increases and/or body size decreases.

$l_{i}(t)=l M n+(l M x-l M n)\left(1-\frac{n m l_{i}}{n l l n p}\right)\left[\frac{w_{i}(t)-w M n}{w M x-w M n}\right]^{e b}$

where $n m l$ is the number of alleles promoting an increased gill-raker count, $n l l$ is the number of loci controlling gillraker count, $n p$ is the number of alleles in a locus, and $e b$ determines the effect of body size on gill-raker spacing; the maximum and minimum gill-raker spacings are $l M x$ and $l M n$, respectively. The default value for $l M x$ is 0.02 , which is twice the body mass of large zooplankton $(=0.01 \mathrm{~g})$. The default value for $l M n$ is 0.001 , which is $10 \%$ of the body mass of large zooplankton. The maximum and minimum fish body masses are $w M x$ and $w M n$, respectively. $w M x$ and $w M n$ were derived from the asymptotic body length of anadromous alewives, $b M x$, and the minimum body length, $b M n$ (Eq.(SI.12)), using the alewife body-length-body-mass relationship (body mass $(\mathrm{g})=$ $10^{-5.289}$ [body length $\left.(\mathrm{mm})\right]^{3.063}$ ) [67]. The default value for $b M x$ is set to $273.684 \mathrm{~mm}$ in order to make the average body length of the largest 5-year-old females approximately equal to the average total body length of adults from three anadromous populations $(=260 \mathrm{~mm})$ [3].

Low gill-raker spacing values could reduce the efficiency of foraging for large prey because closely-spaced gill rakers are more prone to becoming clogged by large prey than more widely spaced rakers. This reduction in foraging efficiency, $p f$, is modeled by Eq. (3).

$$
p f(k, l, l p)= \begin{cases}\left(\frac{l}{k}\right)^{l p} & \text { if } k>l \\ 1 & \text { if } k \leq l\end{cases}
$$


where $k$ is prey body mass and $l p$ (default value $=0.5$ ) controls the decrease in the efficiency of foraging for large prey. Because of the lack of empirical data on $l p$, we performed a local sensitivity analysis to study the effect of $l p$ on the evolution of fish morphology. We acknowledge that the reduced efficiency can be attributed to reduced efficiency of the double pump suction mechanism that allows alewives to pull prey into the mouth while pumping the incoming water out through the opercular openings [18].

\section{Alewives' foraging}

Equation (4) defines the effects of fish body size and gillraker spacing on alewives' foraging for different-sized prey (Fig. 2).

$$
\begin{aligned}
& f e(k, u, l, f s, l p)= \\
& \left\{\begin{array}{l}
p f(k, l, l p) c F(u, l, f s)\left[\frac{1}{1+e^{-f s\left(\log _{10} \frac{k}{u}\right)}}\right]\left[1-\frac{1}{1+e^{-f s\left(\log _{10} \frac{k}{l}\right)}}\right] \text { if } u>l \\
0 \quad \text { if } u \leq l
\end{array}\right.
\end{aligned}
$$

where $f e$ is foraging efficiency; $k$ is prey body mass; the first and second terms in square brackets describe the decrease in the efficiency of foraging for large and small prey, respectively; $p f$ describes the decrease in the efficiency of foraging for large prey due to narrow gill-raker spacing (Eq. (3)); and $f s$ describes the decrease in the efficiency of foraging for very large or very small prey. A high

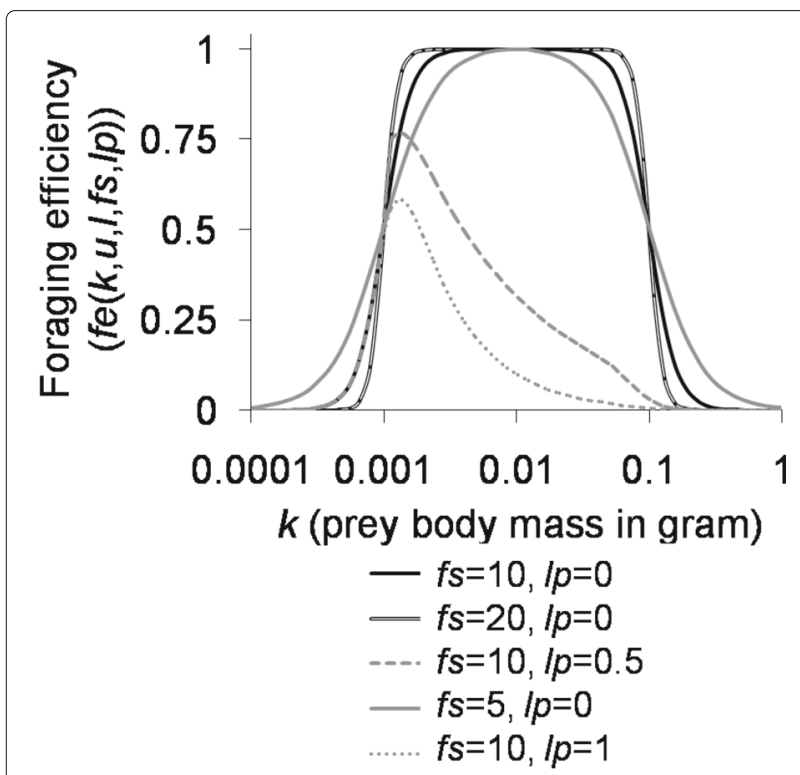

Fig. 2 The foraging efficiency ( $f e$ ) function. $u(=0.1)$ affected the efficiency of foraging for large prey. I (=0.001) affected the efficiency of foraging for small prey. Ip controlled the effect of gill-raker spacing on foraging for large prey. fs controlled the decrease in the efficiency of foraging for very large or very small prey
$f_{S}$ value indicates a rapid decrease in the efficiency of foraging for very large or very small prey. The variables $u$ and $l$ represent gape size and gill-raker spacing, respectively; a foraging efficiency of 0.5 is achieved when $p f(k, l, l p)=1$ and $u>l$. When there is no decrease in the efficiency of foraging for large prey due to narrow gill-raker spacing $(p f(k, l, 0)=1), c F$ set fish foraging efficiency to the maximum $(=1)$ at $\frac{\log _{10} u+\log _{10} l}{2}$ (Eq. (5)).

$$
\begin{aligned}
c F\left(u, l, f_{s}\right) & =\left[\frac{2+e^{-f_{s}\left(\tau-\log _{10} l\right)}+e^{-f_{s}\left(\tau-\log _{10} u\right)}}{e^{-f_{s}\left(\tau-\log _{10} l\right)}}\right], \\
\tau & =\frac{\log _{10} u+\log _{10} l}{2}
\end{aligned}
$$

The model describes the type II functional response to alewives' foraging (Eq.(SI.24)). The effect of the type II functional response on the morphological evolution of fish was studied by performing a sensitivity analysis on $\mathrm{cH}$, which determines the handling time. The default $c H$ value was 0.1 , which reduces the foraging efficiency by $50 \%$ when the prey abundance is $10 \%$ of that predicted by a body mass-abundance relationship derived from ecological power laws (Eq. (8)) [45, 50].

Traditional foraging theories predict that a prey species providing a better net energy return rate should be chosen more often by a predator species [73-76], which is consistent with the observation that alewives interchangeably switch between filter-feeding and particulate-feeding modes as zooplankton size and density change [77]. In this model, an individual spends more foraging time targeting the prey type with the highest total mass (=abundance $x$ body mass) (Eq.(SI.27)).

\section{Alewives' prey (size-structured prey clusters)}

The alewives' prey was divided into multiple sizestructured clusters located at different trophic positions. Two or three prey clusters were simulated, with body masses ranging from $10^{-3} \mathrm{~g}$ to $9.5 \mathrm{~g}$. No empirical data were available to determine the number of prey clusters. When more than three prey clusters were simulated using the default parameter settings, one or more prey clusters went extinct. The representative body masses for the three-cluster setting are $0.01 \mathrm{~g}$, corresponding to the body mass of large zooplankton; $0.224 \mathrm{~g}$, corresponding to the mass of a large fish egg; and $5 \mathrm{~g}$, corresponding to the body mass of small organisms foraging for zooplankton and fish eggs. The representative body masses for the two-cluster setting were $0.01 \mathrm{~g}$ and $0.224 \mathrm{~g}$. For simplicity, we assumed that the alewives' prey was asexuallyreproducing diploid organisms whose body mass was determined by an unlinked-biallelic QTL $(\{0,1\})$. The default number of loci controlling prey body mass is 10 . Therefore, each prey cluster contains 21 discrete body size classes, which are intended to approximate a body 
size spectrum within each cluster while imposing only a modest increase in computation time. The mutation rate of the allele affecting prey body size is set to $10^{-5}$. This food web modeling approach differs from conventional food web modeling approaches that assume a continuous size distribution of species because we aimed to study the contemporary evolution of fish in food webs governed by currently unknown mechanisms.

Prey in a cluster was assumed to (1) forage for smallerbodied clusters (prey), (2) be consumed by larger-bodied clusters (predators) or alewives, and (3) compete with organisms in the same cluster. These trophic interactions and within-trophic competitions are described by the discrete Lotka-Volterra equation (Eq. (6)) [78, 79].

$$
r t_{r, r c}(t)=\frac{1+r I_{r, r c}+p I_{r, r c}(t)}{1+s I_{r}(t)+n I_{r, r c}(t)+f I_{r, r c}(t)}
$$

where $r t$ is the prey abundance before the initiation of dynamic processes within a prey cluster, which is calculated using Eq. (SI.44), and $r I$ is the intrinsic growth rate. $r I$ is 1 for the prey cluster with the smallest representative body mass, and 0 for other prey clusters. $r$ and $r c$ are the indices for a prey cluster and a body size class, respectively. $s I, n I, p I$, and $f I$ describe the effect of competition within a cluster, the effect of prey on predators, the effect of predators on prey, and the effect of fish foraging for prey, respectively. To resolve potential problems relating to the increase in the number of model parameters caused by increasing the number of trophic levels, we used allometric relationships derived from ecological power laws (Eq. (7), Eq. (10), Eq. (12)) to set the parameter values for the discrete Lotka-Volterra equation.

\section{Within-trophic competition among prey}

The effect of competition within a prey cluster on prey abundance, $s I$, is given by Eq. (7).

$$
\begin{aligned}
& s I_{r}(t)=\frac{1}{r a_{r}} \sum_{r c} r s c_{r, r c}(t-1) \\
& r a_{r}=c A\left(r M u_{r}\right)^{-e A}
\end{aligned}
$$

where $r a$ is the prey abundance predicted by the bodymass-abundance relationship, $r s c$ is the prey abundance after computing the dynamics within the prey cluster using Eq. (SI.44), $c A$ (default value $=5.0 \times 10^{6}$ ) is a constant for body mass, $r M u$ is the representative body mass of a prey cluster, and $e A$ is an exponent for body mass. The value of $e A$ has been estimated to be 0.84 based on data gathered at Tuesday Lake in 1984 [80], 0.75 based on data gathered at Tuesday Lake in 1986 [80, 81], and 1.1 based on data gathered at the Ythan Estuary [80]. The default value for $e A$ was set to 0.75 , and the effect of $e A$ on alewife morphological evolution was studied by performing a local sensitivity analysis.

\section{Trophic interactions}

For this model, the prey community represents multiple clusters of organisms. Prey organisms forage for organisms in smaller-bodied prey clusters, and they are foraged by organisms in larger-bodied prey clusters. Thus, the prey community for this model resembles a food web, which contains multiple paths of energy flow. The strength of the interaction between prey clusters is treated as a function of the predator-prey body mass ratio [46-49]. Equation (9) defines $n I$, the effect of predation by a larger-bodied prey cluster (predators) on a smallerbodied prey cluster (prey).

$$
n I_{r, r c}(t)=\sum_{\substack{r k \\ r k \neq r}}\left[f n c\left(\left(\sum_{r c} r s c_{r k, r c}(t-1)\right), i n_{r, r}, \frac{c H_{r k}}{r a_{r}}, b f_{r}\right)\right]
$$

where $f n c$ (Eq.(SI.25)) is a functional response and $c H$ determines handling time. The default value for $\mathrm{cH}$ was set at 0.1 to reduce foraging efficiency by $50 \%$ when the prey abundance was $10 \%$ of that predicted by the bodymass-abundance relationship (Eq. (8)). bf is an exponent for prey abundance. Its default value was set to 1 because we assumed a type II functional response in this work. in was a scaling factor for the effect of predation by a largerbodied prey cluster on a smaller-bodied prey cluster. We used Eq. (10) to calculate in.

$$
i n_{r 1, r 2}= \begin{cases}c i\left(\frac{r M u_{r 1}}{r M u_{r 2}}\right)^{e I} & \text { if } r M u_{r 2} \geq r M u_{r 1} \\ 0 & \text { if } r M u_{r 2}<r M u_{r 1}\end{cases}
$$

where $r 1$ and $r 2$ are indices for a smaller-bodied and a larger-bodied prey cluster, respectively; $c i$ (default value = $2.5 \times 10^{-6}$ ) is a scaling factor for the predator-prey body mass ratio; and $e I$ is an exponent for the predator-prey body mass ratio. The default value for $e I$ was 0.25 , which is the value obtained by using an allometric scaling relationship to approximate the basal metabolic rate per unit body mass $[46,47,49]$.

The effect of the alewives' foraging for prey was modeled using Eq. (11).

$$
\begin{aligned}
& f I_{r, r c}(t)=\sum\left[f c_{r, s} n c_{r, r c}(t) c n\right] \\
& f c_{r}=c n c i\left(\frac{r M u_{r}}{w f}\right)^{e I}
\end{aligned}
$$

The number of size classes in a cluster, $c n$, is used to scale fI such that the per capita effect of foraging for a size class is equal to $f c$ if an individual spends equal amounts of its foraging time targeting each body size class within the prey cluster that provides the maximum foraging efficiency. The representative body mass for alewives, $w f$ (= $30.27 \mathrm{~g}$ ), is the mean body mass of female alewives of the 
largest genotype at the stable-stage distribution; it is calculated from the Leslie matrix shown in Additional file 1: Supporting information I. $n c$ is the number of individuals foraging for prey given by Eq.(SI.43).

Equation (13) describes the effect of smaller-bodied prey clusters on larger-bodied prey.

$$
\begin{aligned}
& p I_{r, r c}(t)=\sum_{\substack{r k \\
r k \neq r}}\left[i p_{r k, r} \sum_{r c} r s c_{r k, r c}(t-1)\right] \\
& i p_{r 2, r 1}=p c \frac{f n c\left(\sum_{r c} r s c_{r 1, r c}(t-1), i n_{r 1, r 2}, \frac{c H_{r 1}}{r a_{r 1}}, b f_{r 1}\right)}{\sum_{r c} r s c_{r 1, r c}(t-1)}
\end{aligned}
$$

where $r 1$ and $r 2$ are indices for a smaller-bodied prey cluster and a larger-bodied prey cluster, respectively; $p c$ (default value $=0.01$ ) was a scaling factor for the predatorprey body mass ratio.

\section{Initial conditions}

During the first 1000 simulated years, only prey were included in the simulation in order to establish stable size-structured prey clusters. Adult alewives (500 males and 500 females) were then introduced into the ecosystem on year 1001. Using the default parameter settings, during the period when only prey was present, the abundance of prey clusters converged to positive numbers. We used the body-mass-abundance relationship (Eq. (8)) to set the prey abundance for the initial time step. The initial abundance distribution of body mass classes in a prey cluster was calculated using the normal distribution (Eq.(SI.46)). The alleles for alewives in the initial population were randomly selected based on known allele frequencies. The default value for the initial frequency of the growth-improving allele $\left(P(A)_{t=0}\right)$ was 0.99 , while that for the frequency of the gill-raker count-increasing allele $\left(P(B)_{t=0}\right)$ was 0.01 . These default parameter settings correspond to a scenario in which a population of anadromous alewives with genetic variation typical of existing anadromous alewives suddenly becomes landlocked. We performed a local sensitivity analysis to study the effect of the initial allele frequencies on the morphological evolution of the fish.

\section{Results}

\section{Alewife morphological changes before and after the first 250 years}

For the first 150-250 years after the alewives were introduced into the ecosystems, their growth $(P(A))$ decreased monotonically and their gill-raker counts $(P(B))$ increased monotonically under most combinations of trophic structure configuration ( 2 or 3 prey clusters), within-trophic competition level $(e A)$, and trophic interactions $(e I)$. After the first $150-250$ years, however, the alewives exhibited divergent evolutionary trajectories under different trophic settings, and some evolutionary trajectories reversed (Fig. 3). In general, after the first 1000 years, the directions of evolutionary changes in the body size and gill raker count were similar to those during years 250-1000 after introduction. Nevertheless, under certain conditions, the directions of evolutionary changes after the first $\sim 1000$ years changed noticeably from those during years 250 1000. Such deviations were observed when: (1) withintrophic competition was weak $(e A=0.75)$, (2) trophic interactions were strong $(e I=0.25)$, (3) reductions in body size substantially increased the alewives' success at foraging for small prey $(e b=0.125)$, and (4) narrow gill-raker spacings had moderate negative effects on the alewives' foraging for large prey $(l p=0.5)$.

Under these conditions, the evolutionary trajectory for one morphological trait reversed during the first 150250 years, and that for the other morphological trait reversed by approximately year 1000 . These results show that knowledge of the food web's structure and the relationships between organisms at different trophic levels is essential for predicting the body size and gill-raker count of landlocked alewives 250 years after their introduction.

Over the first 250 years, there were three clear ways in which changes in the alewives' body size, gill raker spacing, and gill raker count affected their morphological evolutionary trajectory. First, in cases where reductions in the alewives' body size substantially improved their foraging for small prey $(e b \leq 0.25)$, their gill-raker count increased $\left(\left(P(B)_{t=300}-P(B)_{t=0}\right)>0.1\right)$ (Fig. 4). Second, as the effect size of the allele controlling the alewives' growth decreased (i.e. as $b A$ increased), their gill-raker count also increased except in cases where a very small decrease in body size substantially improved their foraging for small prey $(e b=0)$. Third, the rate of change of the gill-raker count increased as small gill-raker spacings became less of a barrier to successful foraging for large prey. For example, there was a monotonic decrease in mean growth and a monotonic increase in the mean gill-raker count over the first 150-250 years when (1) reductions in alewife body size substantially improved their foraging for small prey $(e b \leq 0.25)$ and $(2)$ narrow gill-raker spacings had no or only moderate negative effects on foraging for large prey $(l p=0$ or 0.5$)$. Nevertheless, these trends in the evolution of body size and gill-raker count were not observed in cases where (1) there were three prey clusters, (2) trophic interactions were strong $(e I=0.25)$, (3) within-trophic competition was weak $(e A=0.75)$, and (4) the efficiency of foraging for small prey was substantially increased by very small reductions in alewife body size $(e b=0)$. 

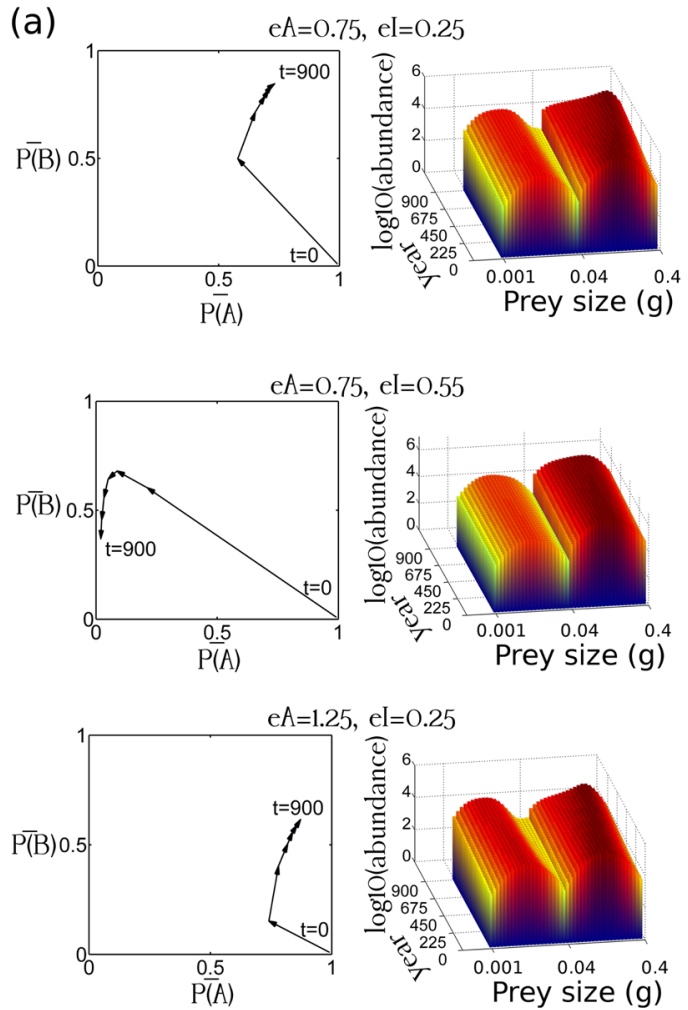

(b)
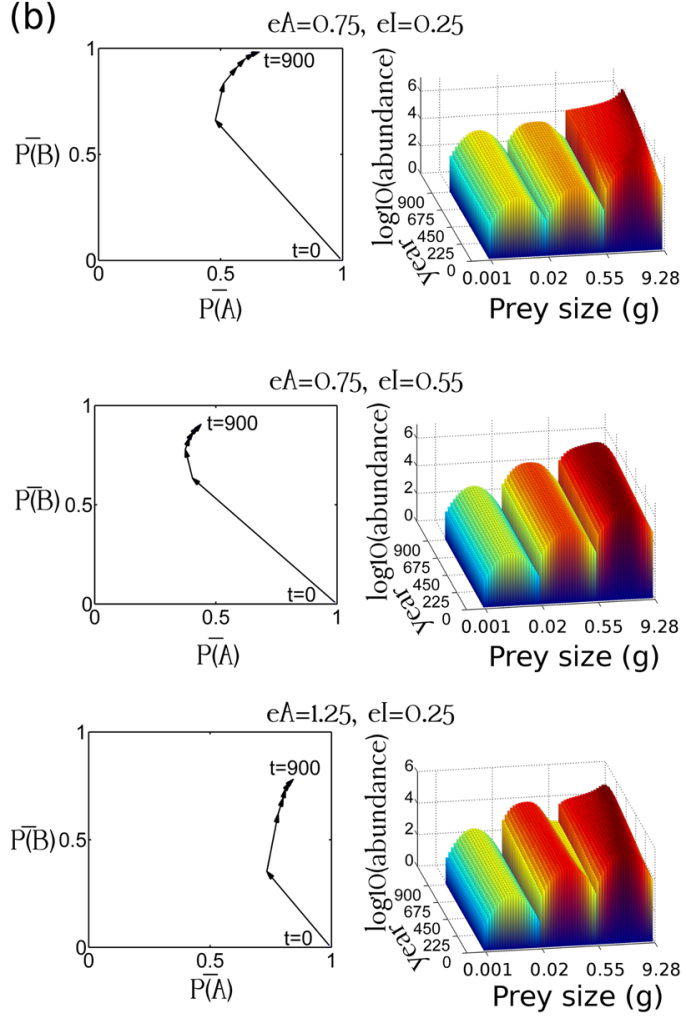

Fig. 3 The effect of within-trophic competition and trophic interactions on alewife morphological evolution and prey abundance in ecosystems with two (a) or three (b) prey clusters. A low eA value indicates a low intensity of within-trophic competition. A low el value denotes strong trophic interactions. $\bar{P}(\bar{A})$ was the mean frequency of the allele improving growth. $\overline{P(B)}$ was the mean frequency of the allele increasing alewives' gill-raker count. Reductions in alewives' body size substantially improved the efficiency of their foraging for small prey $(e b=0.125)$. Narrow gill-raker spacings did not reduce the efficiency of the alewives' foraging for large prey $(l p=0)$. Allele frequencies were recorded every 150 years in this figure

\section{Alewives' foraging efficiency for very large or very small prey}

The gill-raker number increased only in cases where the decrease in the alewives' foraging efficiency for very large or very small prey was moderate $\left(f_{s}=10\right)$ or fast $\left(f_{s}=\right.$ 20). For the first 150 years, the decreases in the alewives' growth and the increases in their gill-raker numbers were greater when $f s=20$ than when $f s=10$ (Additional file 1: Figure SI.3.1).

\section{The functional response}

Changing the handling time in the type II functional response $(h t=0,0.05,0.1,0.25)$ did not appreciably affect the evolutionary trajectory under most of the studied trophic settings. However, the handling time did affect the evolution of the alewives' body size and gill-raker number when (1) there were three prey clusters, (2) within-trophic competition was weak ( $e A=0.75)$, (3) trophic interactions were strong $(e I=0.25)$, (4) reductions in the alewives' body size led to substantial improvements in their foraging for small prey $(e b=0.125)$, and (5) narrow gill-raker spacings had a moderate negative effect on the alewives' foraging for large prey $(l p=0.5)$ (Additional file 1: Figure SI.3.2).

\section{Stochasticity in fish morphological evolution}

The standard deviations of allele frequencies were generally small $\left(\sigma_{P(A)}<0.05 \& \sigma_{P(B)}<0.05\right)$ for the first 300 years when reductions in the alewives' body size moderately improved their foraging for small prey $(e b>=0.5)$ or when very small reductions in their body size substantially improved their foraging for small prey $(e b=0)$. Nonetheless, in other cases the standard deviations of allele frequencies over the first 300 years were above 0.1 . They continued increasing after the first 300 years under several trophic settings when body size reductions substantially improved the alewives' foraging for small prey $(e b=0.125$ or 0.25$)$ and narrow gill-raker spacings had no effect or only moderate negative effects on their foraging for large prey (lp $=0$ or 0.5 ) (Fig. 5). 


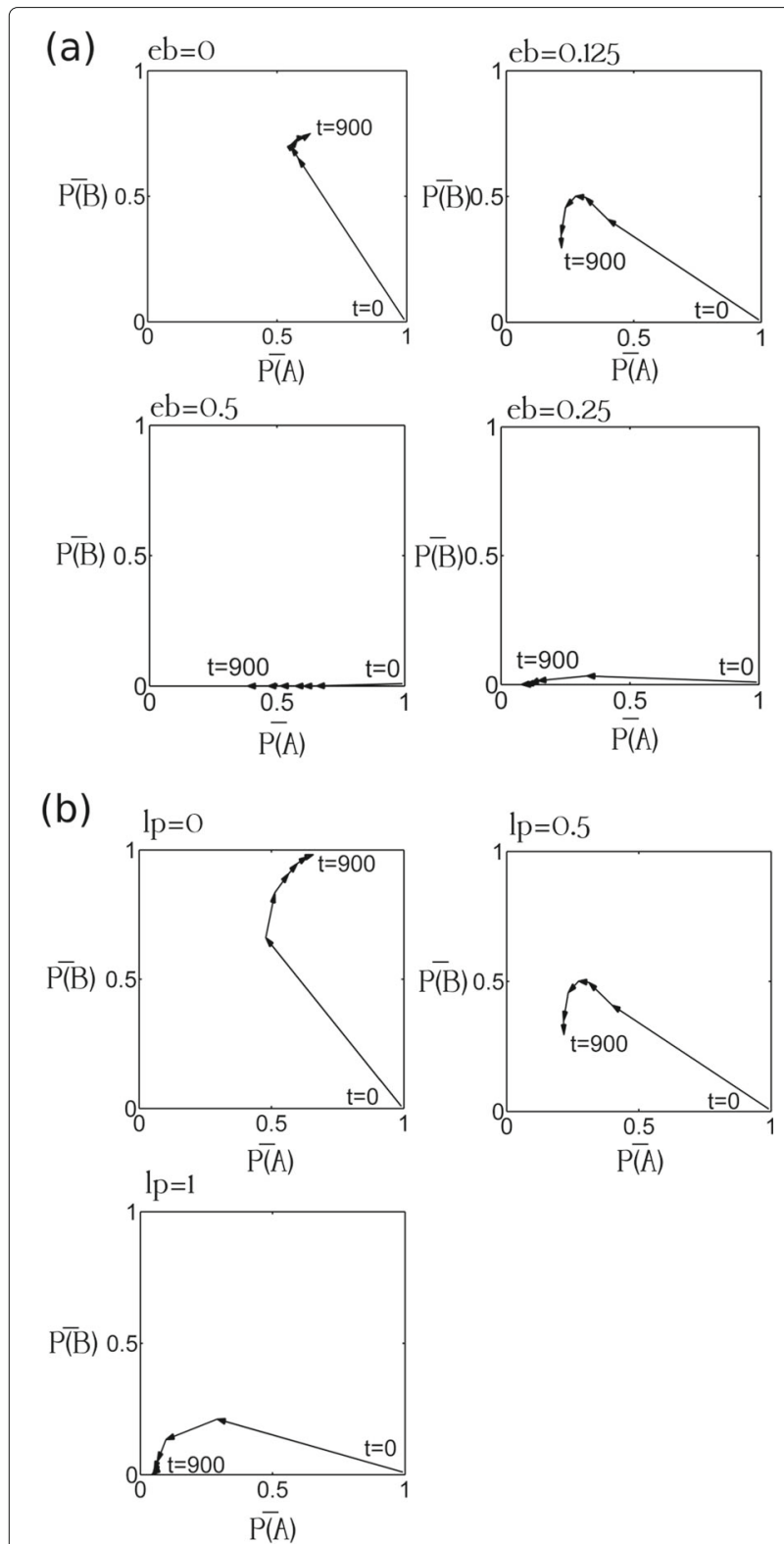

Fig. 4 Alewife morphological evolution affected by a the effect of body size on foraging for small prey and $\mathbf{b}$ the effect of clogged gill rakers on foraging for large prey. A low eb value indicated that alewives' small body size substantially improved the efficiency of their foraging for small prey. A high I $p$ value indicated that alewives' small gill-raker spacing greatly undermine the efficiency of their foraging for large prey. The intensity of within-trophic competitions was low $(e A=0.75) \cdot \mu_{P(A)}$ was the mean frequency of the allele improving alewives' growth. $P(B)$ was the mean frequency of the allele increasing alewives' gill-raker number. Trophic interaction were strong $(e l=0.25)$. Alewives' small gill-raker spacing moderately undermined the efficiency of their foraging for large prey $(I p=0.5)$. Allele frequencies were recorded every 150 years in this figure

\section{Individual stochasticity of growth}

Different degrees of individual stochasticity of alewife growth produced similar morphological evolutionary

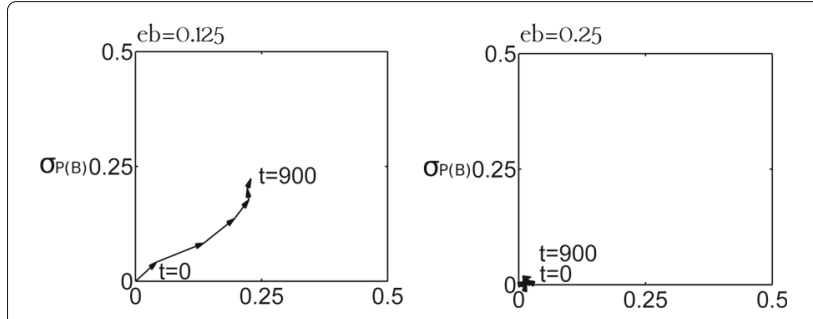

Fig. 5 Stochasticity in alewife morphological evolution. A low eb value indicated that alewives' small body size substantially improved the efficiency of their foraging for small prey. $\theta_{P(A)}$ was the standard deviation of the frequency of the allele improving alewives' growth. $\theta_{P(B)}$ was the standard deviation of the frequency of the allele increasing alewives' gill-raker number. The intensity of within-trophic competitions was moderate $(e A=1)$. Trophic interaction were moderate $(e l=0.4)$. Alewives' small gill-raker spacing did not undermine the efficiency of their foraging for large prey $(I p=0)$. There were three prey clusters. Allele frequencies were recorded every 150 years in this figure

trajectories when there were two prey clusters. In contrast, different degrees of individual growth stochasticity resulted in multiple evolutionary morphological trajectories after the first 150-250 years under most trophic settings featuring three prey clusters. Evolutionary trajectories simulated under high individual growth stochasticity $(b c v=0.2)$ differed from those under intermediate-or-low individual growth stochasticity $(b c v=0.001,0.01,0.1)$ when there were weak or moderate levels of within-trophic competition $(e A=$ 0.75 or 1$)$ and strong trophic interactions $(e I=0.25)$ (Additional file 1: Figure SI.3.3). In addition, evolutionary trajectories simulated under high or low individual growth stochasticity $(b c v=0.2$ or 0.001$)$ differed from those simulated under intermediate individual growth stochasticity $(b c v=0.01,0.1)$ when there was strong within-trophic competition $(e A=1.25)$ and weak trophic interactions $(e I=0.55)$.

\section{Initial morphology of alewives}

For the first 150-250 years, the alewives' body size decreased and their gill-raker number increased when a majority of the initially landlocked alewives had large bodies $\left(P(A)_{t=0} \geq 0.99\right)$ and a low gill-raker counts $\left(P(B)_{t=0} \leq 0.01\right)$, regardless of the initial level of genetic variation. After the first 150-250 years, the evolutionary trajectories simulated under a high initial genetic variation $\left(\left(P(A)_{t=0}=0.99, P(B)_{t=0}=0.01\right)\right.$ differed from those simulated under low initial genetic variation $\left(P(A)_{t=0}=1, P(B)_{t=0}=0 ; P(A)_{t=0}=0.9999, P(B)_{t=0}=\right.$ 0.0001; $P(A)_{t=0}=0.999, P(B)_{t=0}=0.001$ ) (Fig. 6). Under most trophic settings, the two different initial allele frequency combinations (large-body-and-low-gillraker-number, i.e. $P(A)_{t=0} \geq 0.99, P(B)_{t=0} \leq 0.01$, and small-body-and-high-gill-raker-count, i.e. $P(A)_{t=0} \geq$ 


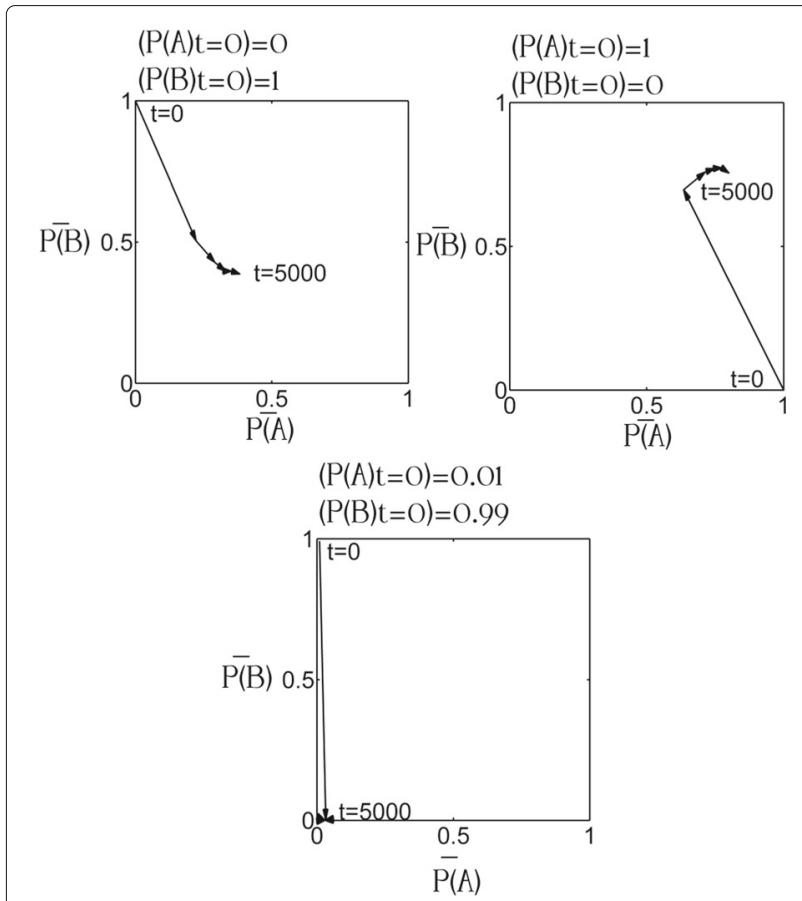

Fig. 6 The effect of the initial allele frequencies on alewife morphological evolution. $P(A)_{t=0}$ was the initial frequency of the allele improving alewives' growth. $P(B)_{t=0}$ was the initial frequency of the allele increasing alewives' gill-raker number. $P(\bar{A})$ was the mean frequency of the allele improving alewives' growth. $P \overline{(B)}$ was the mean frequency of the allele increasing alewives' gill-raker number. The intensity of within-trophic competitions was low ( $e A=0.75)$. Trophic interaction were strong $(e l=0.25)$. The reduction in alewives' body size substantially improved the efficiency of their foraging for small prey $(e b=0.125)$. Alewives' small gill-raker spacing moderately undermined the efficiency of their foraging for large prey $(I p=0.5)$. Allele frequencies were recorded every 1000 years in this figure

0.01, $\left.P(B)_{t=0} \leq 0.99\right)$ resulted in different allele frequencies within 5000 years. The two sets of initial allele frequency settings, however, resulted in similar allele frequencies $\left(P(A)_{t=0} \sim 0.8, P(B)_{t=0} \sim 0.4\right)$ after 5000 years when there were three prey clusters, strong within-trophic competition $(e A=1.25)$, and strong trophic interactions $(e I=0.25)$.

\section{Discussion}

\section{Changes in low trophic levels}

A reasonable description of multiple, low-trophic-level interactions is indispensable for inferring the abundance and morphology of prey species, which can strongly affect the evolution of fish. This is particularly important when considering small and isolated environments because fish can induce rapid low-trophic-level changes in such contexts. For example, in addition to the wellestablished changes in zooplankton communities caused by the introduction of alewives, low-trophic-level changes caused by grass carp, Ctenopharyngodon idella, silver carp, Hypophthalmichthys molitrix, and bighead carp, Hypophthalmichthys nobilis, at Lake Donghu in China have been extensively documented [82]. Grass carp were heavily stocked in the lake during the late 1960s and 1970s, and silver carp and bighead carp have been stocked since the 1970s [83]. The stocked fish reduced the density of Daphnia from 26.1-35.0 ind./L in 1971-1986 to $0.5-1.3$ ind./L in 1987-1996. Moreover, the annual average body length of important prey of silver and bighead carp decreased over this period - from $1.22 \mathrm{~mm}$ (1980) to $0.65 \mathrm{~mm}(1988)$ in the case of Daphnia hyalina, from $1.33 \mathrm{~mm}(1980)$ to $0.78 \mathrm{~mm}$ (1987) for Daphnia carinata, and from $0.81 \mathrm{~mm}$ to $0.61 \mathrm{~mm}$ (1992) for Daphnia brachyurum [84-88]. A decrease in the densities of Daphnia, rotifers, and protozoans relaxed the competition among small zooplankton, leading to an increase in protozoan biomass [82]. The total annual average densities of zooplankton observed in the 1990s were between 15 and 20 times greater than those recorded in the 1960s, mainly because of this increase in protozoan biomass. The protozoan biomass increase contributed to an increase in the mean annual fish standing crop, from $95.3 \mathrm{~kg} / \mathrm{ha}$ in the $1960 \mathrm{~s}$ to $945.1 \mathrm{~kg} / \mathrm{ha}$ in the 1990s. In this study, alewives were found to affect the abundance and morphology of their prey, which in turn changed the abundance and morphology of the alewives. Complex low-trophic-level interactions can thus alter the abundance and characteristics of fish species. Consequently, it is not sufficient for fisheries management models to merely describe a few predator-prey interactions; a much more detailed description of trophic interactions is required. More accurate and reliable predictions of low-trophic-level changes will improve not only the prediction of fish morphology and abundance but also the management of aquatic ecosystems.

\section{Ontogenetic changes, trophic interactions, and competition}

Selection forces can act differently on fish at different life stages (or ages), and they can change over time. For example, individuals at different life stages (or ages) may forage for different-sized prey, and the strength of competition may differ between life stages. For this reason, we explicitly modeled the ontogenetic changes in the alewives' foraging characteristics. Describing ontogenetic changes complicated the model but improved the description of resource competition among fish and the representation of trophic interactions.

\section{Trade-offs between morphological traits}

Instead of assuming abstract, theoretical fitness tradeoffs, the model explicitly describes trade-offs between body size and gill raker numbers by reflecting findings 
from empirical studies and potential relationships derived from the mechanical properties of foraging traits. Although this modeling approach increased the number of model parameters, it facilitated the identification of knowledge gaps and model parameterization. In the final model, the body size effect on the gill-raker function $(e b)$ and the small gill raker effect on alewives' foraging for large-bodied prey $(l p)$ determine whether the gill-raker number increases during the first 150-250 years. These two properties of alewives' morphology are trade-offs related to their foraging for different prey types, which can cause divergent natural selection between and within populations exploiting different prey [89-92]. Although both parameters are important for predicting the morphological evolution of alewives, they have not been empirically estimated. Detailed empirical studies on fish foraging will be needed to provide robust parameter estimates and better explanations of the ecological processes related to foraging in fish; once obtained, this information could be used to further improve the prediction of morphological evolution in fish.

\section{Limitations of this model}

This study focused on the effects of species at low trophic levels (prey of alewives) on alewife morphological evolution, and the model does not account for all of the factors that could potentially affect the evolution of alewife body size and gill raker numbers. In particular, to limit complexity, it omits any description of alewives' predators, even though alewives are common prey for several fish species [35, 93]. In addition, environmental effects on alewives' growth and sexual maturation were excluded, although they could be accounted for by adjusting the values of relevant parameters such as $c e$. Further studies using this model could be conducted to explore the evolution of fish morphology under different environmental conditions and in the presence of different environmental effects on fish growth and sexual maturation.

\section{Conclusions}

Simulations using a newly developed model showed that alewives' gill-raker counts only increased during the first 150-250 years after their introduction into a lake if reductions in their body size substantially improved their foraging for small prey. In addition, their gillraker counts increased to a greater degree as narrow gill-raker spacings became less of a barrier to foraging for large prey. Under most trophic settings, the alewives' body sizes decreased monotonically over the first 150-250 years, while their gill-raker counts increased monotonically. After the first $150-250$ years, however, the alewives exhibited multiple evolutionary trajectories under different trophic settings; in some cases, the evolutionary trajectories established over the first 150-250 years were subsequently reversed. This study suggests that the current morphology of recently ( $\sim 300$ years)landlocked alewives may not represent an evolutionarily stable state.

\section{Additional file}

Additional file 1: Contains supporting information I, II, and III. (PDF 833 kb)

\section{Abbreviations}

bA: Parameter controlling the minimum asymptotic body length; bcv: Coefficient variation of body length growth; bf: Exponent for prey density in a functional response; bMn: Minimum body length; bMx: Maximum body length; bO: Body length; cA: Scaling factor for species body mass-abundance relationship; CF: The function controlling the foraging efficiency at the midpoint between $\log _{10} t u$ and $\log _{10}$ t/ to 1 when $/ p=0 ; \mathrm{cH}$ : Parameter controlling handling time; ci: scaling factor for in; $\mathrm{cn}$ : Number of size classes for a prey cluster; eA: Exponent for body-mass-abundance relation; eb: Effect of body size on fish's foraging for small prey; el: Exponent for predator-prey body mass ratio; fc: A scaling factor for the effect of foraging by an individual fish on a size class of a prey cluster; fe: Fish foraging efficiency; fl: Effect of fish foraging for prey; fnc: Functional response; fs: Parameter controlling the difference between the efficiency of foraging on small (or the large) resources and that on medium-sized resources; ht: Handling time; in: Coefficient for the effect of predators on prey; k: Prey body mass; l: Gill raker spacing; IMn: Minimum value for l; IMx: Maximum value for l; Ip: Parameter controlling a decrease in fish foraging efficiency due to small gill-raker spacing; nc: Number of individuals foraging for a resource; nl: Effect of prey on predators; nll: Number of loci controlling the lower-foraging bound; nml: Number of alleles lowering the lower-foraging bound; np: Number of alleles for a locus; NMFS: National Marine Fisheries Service; $P(A)$ : Frequency of the allele increasing body size; $P(B)$ : Frequency of the allele decreasing gill-raker spacing; pc: Scaling factor for ip; pf: Decrease in the foraging efficacy caused by small gill raker spacing; pl:

Effect of predators on prey; QTL: Quantitative trait locus; r: Prey cluster; ra: Expected abundance of a prey cluster; rc: A size class in a prey cluster; rl: Intrinsic growth rate; rMu: Representative body mass of a prey cluster; rsc: Abundance of prey in a size class of a prey cluster after the genetic mutation of prey; rt: Abundance of a resource before mutation; $r 1$ : A prey cluster; $r 2$ : A prey cluster; sl: Effect of competition within a cluster; SI: Supporting information; u: Gape size; wf: Representative body mass; wMx: Maximum fish body masses; wMn: Minimum fish body masses; $\sigma_{\rho}$ : Standard deviations of allele frequency

\section{Acknowledgements}

We would like to thank J. O. Wickman, D. Takahashi, P. Fransson, and M. Fardisi for reviewing our manuscript. J. O. Wickman helped the data visualization. K. Ø Gjelland and O. T. Sandlund provided the parameter estimates regarding the relation between fish body mass and fertility.

Funding

Kempe foundation provided financial support for this study.

\section{Availability of data and materials}

The computer code will can be found on DRYAD repository [94].

\section{Authors' contributions}

JK participated to study conception and carried out the model development, the model programming, and the model analysis. JK drafted the manuscript. XTP initiated the project, participated to study conception, and improved the manuscript. Both authors read and approved the final manuscript.

\section{Competing interests}

The authors declare no conflict of interest.

Consent for publication

Not applicable.

Ethics approval and consent to participate Not applicable. 


\section{Author details}

${ }^{1}$ The Center for Quantitative Sciences in Biomedicine, North Carolina State University, Campus Box 8213, 308 Cox Hall, 27695-8212 Raleigh, NC, USA. ${ }^{2}$ Icelab and Department of Ecology and Environmental Science, Umeå University, Linnaeus văg 6, Umeå, Sweden.

Received: 21 October 2016 Accepted: 14 February 2017 Published online: 27 February 2017

\section{References}

1. Schluter D, McPhail JD. Ecological character displacement and speciation in sticklebacks. Am Nat. 1992;140(1):85-108.

2. Skulason S, Snorrason SS, Jonsson B. Sympatric morphs, populations and speciation in freshwater fish with emphasis on arctic charr. Evol Biol Divers. 1999;70-92.

3. Palkovacs EP, Dion KB, Post DM, Caccone A. Independent evolutionary origins of landlocked alewife populations and rapid parallel evolution of phenotypic traits. Mol Ecol. 2008;17(2):582-97.

4. Kahilainen KK, Siwertsson A, Gjelland KØ, Knudsen R, Bøhn T, Amundsen $P$. The role of gill raker number variability in adaptive radiation of coregonid fish. Evol Ecol. 2011;25(3):573-88.

5. Olden JD, Poff NL, Bestgen KR. Life-history strategies predict fish invasions and extirpations in the Colorado River Basin. Ecol Monogr. 2006;76(1):25-40.

6. Cornwell WK, Schwilk DW, Ackerly DD. A trait-based test for habitat filtering: convex hull volume. Ecology. 2006;87(6):1465-71.

7. Winemiller KO. Ecomorphological diversification in lowland freshwater fish assemblages from five biotic regions. Ecol Monogr. 1991;61(4):343-65.

8. McGill BJ, Enquist BJ, Weiher E, Westoby M. Rebuilding community ecology from functional traits. Trends Ecol Evol. 2006;21(4):178-85.

9. Blumenshine SC, Lodge DM, Hodgson JR. Gradient of fish predation alters body size distributions of lake benthos. Ecology. 2000;81(2):374-86.

10. Rice JA, Crowder LB, Rose KA. Interactions between size-structured predator and prey populations: experimental test and model comparison. Trans Am Fish Soc. 1993;122(3):481-91.

11. Palkovacs EP, Mandeville EG, Post DM. Contemporary trait change in a classic ecological experiment: rapid decrease in alewife gill-raker spacing following introduction to an inland lake. Freshw Biol. 2014;59(9):1897-901.

12. Brooks JL, Dodson SI. Predation, body size, and composition of plankton. Science. 1965;150(3692):28-35.

13. Hutchinson BP. The effect of fish predation on the zooplankton of ten Adirondack lakes, with particular reference to the alewife, Alosa pseudoharengus. Trans Am Fish Soc. 1971;100(2):325-35.

14. Kohler CC, Ney JJ. Consequences of an alewife die-off to fish and zooplankton in a reservoir. Trans Am Fish Soc. 1981;110(3):360-9.

15. Wells L. Effects of alewife predation on zooplankton populations in Lake Michigan. Limnol Oceanogr. 1970;15(4):556-65.

16. Warshaw SJ. Effects of alewives (Alosa pseudoharengus) on the zooplankton of Lake Wononskopomuc, Connecticut. Limnol Oceanogr. 1972;17(6):816-25.

17. Harman WN, Albright MF, Warner DM. Trophic changes in Otsego Lake, NY following the introduction of the alewife (Alosa psuedoharengus). Lake Reserv Manag. 2002;18(3):215-26.

18. Palkovacs EP, Post DM. Eco-evolutionary interactions between predators and prey: can predator-induced changes to prey communities feed back to shape predator foraging traits. Evol Ecol Res. 2008;10:699-720.

19. Post DM, Palkovacs EP. Eco-evolutionary feedbacks in community and ecosystem ecology: interactions between the ecological theatre and the evolutionary play. Philos Trans R Soc B Biol Sci. 2009;364(1523):1629-40.

20. Post DM, Palkovacs EP, Schielke EG, Dodson SI. Intraspecific variation in a predator affects community structure and cascading trophic interactions. Ecology. 2008;89(7):2019-32.

21. Gross RW. Some observations on the landlocked alewife, Pomolobus prezuloharengus (Wilson). N J Fish Surv Rep. 1953;2:157-64.

22. Norden CR. Age, growth and fecundity of the alewife, Alosa pseudoharengus (Wilson), in Lake Michigan. Trans Am Fish Soc. 1967;96(4):387-93.

23. Miller RR. Origin and dispersal of the alewife, Alosa pseudoharengus, and the gizzard shad, Dorosoma cepedianum, in the Great Lakes. Trans Am Fish Soc. 1957;86(1):97-111.
24. O'Gorman R, Lantry BF, Schneider CP. Effect of stock size, climate, predation, and trophic status on recruitment of alewives in Lake Ontario, 1978-2000. Trans Am Fish Soc. 2004;133(4):855-67.

25. Schielke EG, Palkovacs EP, Post DM. Eco-evolutionary feedbacks drive niche differentiation in the alewife. Biol Theory. 2011;6(3):211-9.

26. Jones AW, Palkovacs EP, Post DM. Recent parallel divergence in body shape and diet source of alewife life history forms. Evol Ecol. 2013;27(6): 1175-87.

27. Mcphee MV, Noakes DLG, ALLendorf FW. Developmental rate: a unifying mechanism for sympatric divergence in postglacial fishes?. Curr Zool. 2012;58(1):21-34.

28. Mullen DM, Fay CW, Moring JR. Alewife, Blueback Herring. Washington: Fish and Wildlife Service, US Department of the Interior; 1986.

29. Scott WB, Crossman EJ. Freshwater Fishes of Canada. Oakville: Galt House Publications; 1998.

30. Raney EC, Massmann WH. The fishes of the tidewater section of the Pamunkey River, Virginia. J Wash Acad Sci. 1953;43(12):424-32.

31. Mansueti RJ. Eggs, larvae, and young of the hickory shad, Alosa mediocris, with comments on its ecology in the estuary. Chesap Sci. 1962;3(3): $173-205$.

32. O'Neill JT. Aspects of the life histories of anadromous alewife and the blueback herring, Margaree River and Lake Ainsle, Nova Scotia, 1978-1979. Master's thesis. Acadia University, Wolfville, Nova Scotia, Canada 1980.

33. Palkovacs EP, Hasselman DJ, Argo EE, Gephard SR, Limburg KE, Post DM, Schultz TF, Willis TV. Combining genetic and demographic information to prioritize conservation efforts for anadromous alewife and blueback herring. Evol Appl. 2014;7(2):212-26.

34. Thunberg BE. Olfaction in parent stream selection by the alewife (Alosa pseudoharengus). Anim Behav. 1971;19(2):217-25.

35. Gibson AJF. Dynamics and management of anadromous alewife (Alosa pseudoharengus) populations. Ph.D thesis. Dalhousie University, Halifax, Nova Scotia, Canada 2004.

36. Messieh SN. Population structure and biology of alewives (Alosa pseudoharengus) and blueback herring (A, aestivalis) in the Saint John River, New Brunswick. Environ Biol Fish. 1977;2(3):195-210.

37. Smith SH. Species interactions of the alewife in the Great Lakes. Trans Am Fish Soc. 1970;99(4):754-65.

38. Brandt SB, Mason DM, Macneill DB, Coates T, Gannon JE. Predation by alewives on larvae of yellow perch in Lake Ontario. Trans Am Fish Soc. 1987;116(4):641-5.

39. Eck GW, Wells L. Recent changes in Lake Michigan's fish community and their probable causes, with emphasis on the role of the alewife (Alosa pseudoharengus). Can J Fish Aquat Sci. 1987;44(S2):53-60.

40. Crowder LB. Alewife, rainbow smelt and native fishes in Lake Michigan: competition or predation?. Environ Biol Fish. 1980;5(3):225-33.

41. Crowder LB. Ecological and morphological shifts in lake michigan fishes: glimpses of the ghost of competition past. In: Contemporary Studies on Fish Feeding: the Proceedings of GUTSHOP'84. Netherlands: Springer; 1986. p. 147-58.

42. Bigelow HB, Schroeder WC. Fishes of the Gulf of Maine vol. 53. Washington: US Government Printing Office; 1953.

43. Bigelow HB, Schroeder WC. Fishes of the Gulf of Maine. Edited by BC Collette and G. Klein-MacPhee. Washington: Smithsonian Institution Press; 2002.

44. Walters AW, Barnes RT, Post DM. Anadromous alewives (Alosa pseudoharengus) contribute marine-derived nutrients to coastal stream food webs. Can J Fish Aquat Sci. 2009;66(3):439-48.

45. Marquet PA. Of predators, prey, and power laws. Science. 2002;295(5563): 2229-30.

46. West GB, Brown JH, Enquist BJ. A general model for the origin of allometric scaling laws in biology. Science. 1997;276(5309):122-6.

47. Brown JH, Gillooly JF. Ecological food webs: high-quality data facilitate theoretical unification. Proc Natl Acad Sci. 2003;100(4):1467-8.

48. Emmerson MC, Raffaelli D. Predator-prey body size, interaction strength and the stability of a real food web. J Anim Ecol. 2004;73(3):399-409.

49. O'Gorman EJ, Jacob U, Jonsson T, Emmerson MC. Interaction strength, food web topology and the relative importance of species in food webs. J Anim Ecol. 2010;79(3):682-92.

50. Jennings $S$, Mackinson S. Abundance-body mass relationships in size-structured food webs. Ecol Lett. 2003;6(11):971-4.

51. Kleiber M. Body size and metabolism. ENE. 1932;1:9. 
52. Svärdson G. Speciation of Scandinavian Coregonus [fresh water fish, Sweden]. Rep-Inst Freshw Res. 1979.

53. Rogers SM, Bernatchez L. The genetic architecture of ecological speciation and the association with signatures of selection in natural lake whitefish (coregonus sp. salmonidae) species pairs. Mol Biol Evol. 2007;24(6):1423-38

54. von Bertalanffy L. Principles and theory of growth. Fundam Asp Normal Malignant Growth. 1960;493.

55. Lackey RT. Observations on newly introduced landlocked alewives in Maine. N Y Fish Game J. 1970;17(2):110-6.

56. Joseph EB, Davis J. A preliminary assessment of the river herring stocks of lower Chesapeake Bay. Virginia Inst Marine Sci Species Sci Rep. 1965;51: $1-23$.

57. Marcy Jr BC. Age determinations from scales of Alosa pseudoharengus (Wilson) and Alosa aestivalis (Mitchill) in Connecticut waters. Trans Am Fish Soc. 1969;98(4):622-30.

58. Bagenal TB. A short review of fish fecundity. Biol Basis Freshw Fish Prod. 196789-111.

59. Gross MR. Evolution of diadromy in fishes. In: American Fisheries Society Symposium. Bethesda: American Fisheries Society; 1987. p. 14-25.

60. Keast A, Webb D. Mouth and body form relative to feeding ecology in the fish fauna of a small lake, Lake Opinicon, Ontario. J Fish Board Canada. 1966:23(12):1845-74

61. Popova OA. The predator-prey relationship among fish. The biological basis of freshwater fish production. New York: Wiley; 1967. pp. 359.

62. Popova OA. The role of predaceous fish in ecosystems. Ecol Freshw Fish Prod. 1978;215-49.

63. Nielsen LA. Effect of walleye (Stizostedion vitreum vitreum) predation on juvenile mortality and recruitment of yellow perch (Perca flavescens) in Oneida Lake, New York. Can J Fish Aquat Sci. 1980;37(1):11-19.

64. Persson L. Predicting ontogenetic niche shifts in the field: what can be gained by foraging theory? In: Behavioural Mechanisms of Food Selection. Berlin Heidelberg: Springer; 1990. p. 303-21.

65. Juanes F, Stouder DJ, Feller KL. What determines prey size selectivity in piscivorous fishes? In: Stouder DJ, Fresh KL, Feller RJ, editors. Theory and Application in Fish Feeding Ecology. Columbia: The University of South Carolina Press; 1994. p. 79-100.

66. Kohler CC, Ney JJ. Piscivority in a land-locked alewife (Alosa pseudoharengus) population. Can J Fish Aquat Sci. 1980;37(8):1314-7.

67. Schneider JC. Manual of Fisheries Survey Methods II: with Periodic Updates. Lancing: Michigan Department of Natural Resources, Fisheries Division; 2000.

68. Drenner RW. The feeding mechanics of the gizzard shad (Dorosoma cepedianum). Lawrence: University of Kansas; 1977.

69. Sanderson SL, Cheer AY, Goodrich JS, Graziano JD, Callan WT. Crossflow filtration in suspension-feeding fishes. Nature. 2001;412(6845):439-41.

70. Smith JC, Sanderson SL. Intra-oral flow patterns and speeds in a suspension-feeding fish with gill rakers removed versus intact. Biol Bull. 2008;215(3):309-18.

71. MacNeill DB, Brandt SB. Ontogenetic shifts in gill-raker morphology and predicted prey capture efficiency of the alewife, Alosa pseudoharengus. Lawrence: Copeia; 1990. pp. 164.

72. Friedland KD, Ahrenholz DW, Smith JW, Manning M, Ryan J. Sieving functional morphology of the gill raker feeding apparatus of Atlantic menhaden. J Exp Zool. 2006;305:974-85.

73. Schoener TW. Theory of feeding strategies. Annu Rev Ecol Syst. 1971;2(1): 369-404.

74. Charnov EL. Optimal foraging, the marginal value theorem. Theor Popul Biol. 1976;9(2):129-36

75. Stephens DW, Krebs JR. Foraging Theory. Princeton: Princeton University Press; 1986

76. Scharf FS, Juanes F, Rountree RA. Predator size-prey size relationships of marine fish predators: interspecific variation and effects of ontogeny and body size on trophic-niche breadth. Mar Ecol Prog Ser. 2000;208:229-48.

77. Janssen J. Feeding modes and prey size selection in the alewife (Alosa pseudoharengus). J Fish Board Canada. 1976;33(9):1972-5.

78. Leslie PH. A stochastic model for studying the properties of certain biological systems by numerical methods. Biometrika. 1958;45(1-2): 16-31.

79. Liu P, Elaydi SN. Discrete competitive and cooperative models of Lotka-Volterra type. J Comput Anal Appl. 2001;3(1):53-73.
80. Reuman DC, Mulder C, Raffaelli D, Cohen JE. Three allometric relations of population density to body mass: theoretical integration and empirical tests in 149 food webs. Ecol Lett. 2008;11(11):1216-28.

81. Jonsson T, Cohen JE, Carpenter SR. Food webs, body size, and species abundance in ecological community description. Adv Ecol Res. 2005;36: $1-84$.

82. Yang YF, Huang XF, Liu JK, Jiao NZ. Effects of fish stocking on the zooplankton community structure in a shallow lake in China. Fish Manag Ecol. 2005;12(2):81-9.

83. Ni LY. Study on structure and biomass of aquatic vegetation and its long-term changes in the Donghu Lake, Wuhan. Studies on Ecology of Lake Donghu (II). Beijing: Science Press; 1995. pp. 287.

84. Huang XF, Chen XM, Wu ZT, Hu CY. Studies on changes in abundance and biomass of zooplankton in Lake Donghu, Wuhan. Acta Hydrobiologia Sinica. 1984;8(3):345-58.

85. Chunhou L, Xiangfei H. Species succession of Cladocera in Lake Donghu in relation to various ecological factors [J]. Acta Hydrobiologica Sinica. 1992;2:001.

86. Yang $Y$, Chen $X$, Huang X. Ecological changes of copepods in Lake Donghu, Wuhan Studies on Ecology of Lake Donghu (II). Beijing: Science Press; 1995. pp. 235.

87. Yang $Y$, Huang $X$, Liu J. Long-term changes in crustacean zooplankton and water quality in a shallow, eutrophic Chinese lake densely stocked with fish. Hydrobiologia. 1998;391(1-3):193-201.

88. Yang Y, May L, Gunn IDM, Huang X, Liu J. Comparative studies on effects of predation by fish on Daphnia in Lake Donghu (China) and Loch Leven (Scotland). Technical report. 1999;AK-SG-99-01:265-281.

89. Smith TB. Bill size polymorphism and intraspecific niche utilization in an African finch. Nature. 1987;329:717-9.

90. Norton SF. A functional approach to ecomorphological patterns of feeding in cottid fishes. Environ Biol Fish. 1995;44(1-3):61-78.

91. Huckins CJF. Functional linkages among morphology, feeding performance, diet, and competitive ability in molluscivorous sunfish. Ecology. 1997;78(8):2401-14.

92. Nemeth D. Modulation of attack behavior and its effect on feeding performance in a trophic generalist fish. J Exper Biol. 1997;200(15): 2155-64.

93. O'Gorman R, Schneider CP. Dynamics of alewives in lake ontario following a mass mortality. Trans Am Fish Soc. 1986;1 15(1):1-14.

94. Kang JK, Thibert-Plante X. Data from: Eco-Evolution in Size-Structured Ecosystems: Simulation Case Study of Rapid Morphological Changes in Alewife. Dryad Digit Repository. 2017. http://dx.doi.org/10.5061/dryad. 67c7q. Accessed 17 Feb 2017.

\section{Submit your next manuscript to BioMed Central} and we will help you at every step:

- We accept pre-submission inquiries

- Our selector tool helps you to find the most relevant journal

- We provide round the clock customer support

- Convenient online submission

- Thorough peer review

- Inclusion in PubMed and all major indexing services

- Maximum visibility for your research

Submit your manuscript at www.biomedcentral.com/submit
Biomed Central 